\title{
RESEARCH
}

\section{One-year follow-up of a therapeutic lifestyle intervention targeting cardiovascular disease risk}

\author{
Andrew Wister PhD, Nadine Loewen MD, Holly Kennedy-Symonds MHSc, Brian McGowan MD, \\ Bonnie McCoy MA, Joel Singer PhD
}

$\infty \quad$ See related article page 887

\section{ABSTRACT}

Background: In this study, we tested the efficacy of a lowintensity lifestyle intervention aimed at reducing the risk of cardiovascular disease among mid-life individuals.

Methods: We conducted a randomized controlled trial in which participants were randomly assigned either to receive a health report card with counselling (from a Telehealth nurse) on smoking, exercise, nutrition and stress or to receive usual care. The patients were divided into 2 groups on the basis of risk: the primary prevention group, with a Framingham risk score of $10 \%$ or higher (intervention, $n=157$; control, $n=158$ ), and the secondary prevention group, who had a diagnosis of coronary artery disease (intervention, $n=153$; control, $n=$ 143). The primary outcome was a change in the Framingham global risk score between baseline and 1-year follow-up. Data were analyzed separately for the 2 prevention groups using an intention-to-treat analysis controlling for covariates.

Results: Within the primary prevention group, there were statistically significant changes for the treatment group relative to the controls, from baseline to year 1, in Framingham score (intervention, -3.10 [95\% confidence interval $(\mathrm{Cl})-3.98$ to -2.22 ]; control, -1.30 [95\% Cl -2.18 to -0.42$] ; p<0.01$ ) and scores for total cholesterol (intervention, $-0.41[95 \% \mathrm{Cl}-0.59$ to -0.23$]$; control, -0.14 [95\% Cl -0.32 to 0.04$] ; p<0.05$ ), systolic blood pressure (intervention, -7.49 [95\% Cl-9.97 to -5.01$]$; control, -3.58 [95\% $\mathrm{Cl}-6.08$ to -1.08$] ; p<0.05$ ), nutrition level (intervention, 0.30 [ $95 \% \mathrm{Cl} 0.13$ to 0.47 ]; control, -0.05 [95\% Cl -0.22 to 0.12 ]; $p<$ 0.01 ), and health confidence (intervention, $0.20[95 \% \mathrm{Cl} 0.09$ to 0.31 ]; control, 0.04 [ $95 \% \mathrm{Cl}-0.07$ to 0.15$] ; p<0.05$ ), with adjustment for covariates. No significant changes in outcome variables were found for the secondary prevention group.

Interpretation: We found evidence for the efficacy of an intervention addressing multiple risk factors for primary prevention at 1 year using Framingham risk score report cards and telephone counselling. (Requirement for clinical trial registration waived [enrolment completed before requirement became applicable].)

Une version française de ce résumé est disponible à l'adresse www.cmaj.ca/cgi/content/full/I77/8/859/DCI

CMAJ 2007;177(8):859-65
$\mathrm{C}$ ardiovascular disease remains the leading cause of death in Canada and elsewhere, accounting for $36 \%$ of all deaths in this country. ${ }^{1}$ The total cost of cardiovascular disease to the health care system in 1998 was estimated at nearly \$I8.5 million, which accounts for a striking II. $6 \%$ of the costs of all illnesses. ${ }^{1}$ Although ageadjusted mortality rates for cardiovascular disease have fallen modestly over the past 3 decades, ${ }^{2}$ the absolute number of people with cardiovascular disease or related heart problems will continue to rise as the baby boom generation ages. ${ }^{3}$

Effective prevention and risk reduction programs for cardiovascular disease tend to be multidisciplinary interventions with self-care components tailored to individual risk factors. ${ }^{4-8}$ These programs use evidence-based recommendations for prevention linked to lipid levels, blood pressure, glucose levels and various aspects of lifestyle, including smoking cessation, physical activity, weight management, nutrition and stress management. Typically, they employ what has been called the "expert patient model," an approach that teaches people how to identify and reach health behaviour goals through a combination of self-direction and professional support. However, cardiovascular risk reduction programs often require significant health care resources, they do not incorporate long-term maintenance of behaviour change and follow-up, ${ }^{10,11}$ and they have not been developed with a view to reaching a wide at-risk population. ${ }^{12}$ In response to these research gaps, this project was designed to test the efficacy of the "Simon Fraser Heart Health Report Card System," which employs the Framingham risk scoring methodology $^{13,14}$ to measure global cardiovascular risk levels and to identify targets, which are then distributed in an annual report card to participants and their physicians. The report card was coupled with evidence-based prevention knowledge aimed at motivating participants to change their risk factors through a Telehealth counselling approach.

From the Department of Gerontology (Wister), Simon Fraser University; Fraser Health (Loewen); Acute Care and Special Projects, Burnaby Hospital, Fraser Health (Kennedy-Symonds); Emergency Medicine, Burnaby Hospital, Fraser Health (McGowan), Burnaby, BC; Centre for Health Economics in Cancer, BC Cancer Research Centre (McCoy); Department of Health Care and Epidemiology (Singer), University of British Columbia, Vancouver, BC 


\section{Methods}

\section{Study participants}

This study aimed to reduce cardiovascular risk among people in midlife who were living in the Fraser Health Region (the largest health region in British Columbia, with more than I. 5 million residents, of whom 422 ooo or about $25 \%$ were $45^{-64}$ years of age $\mathrm{e}^{15}$ at the time of the study). First, we sent a letter to all physicians' offices in the region asking for their help in recruiting participants for the study. Second, given the population-based perspective, advertisements were published in local newspapers, interviews were conducted for broadcast by local radio stations, and posters were sent electronically to large employers. Recruitment occurred between Apr. I5, 2002, and Nov. I0, 2004.

The 3 eligibility criteria were age $45^{-6}-6$ years, residence in the Fraser Health region and cardiovascular risk profile according to the literature for primary and secondary prevention. ${ }^{16-18}$ Because evidence-based guidelines recommend different counselling protocols for primary and secondary cardiovascular prevention, the primary and secondary prevention groups for this study were identified and randomized separately. Participants in the primary prevention group had an absolute Framingham risk score of 10\% or higher over a Io-year period (considered the minimum level for effective treatment outcomes). Participants in the secondary prevention group had a diagnosis of coronary artery disease.

Ethics approval was received from both Simon Fraser University and Fraser Health Authority.

\section{Randomization}

After the research coordinator (B. McCoy) obtained consent from a participant who met the eligibility criteria, the person's primary or secondary prevention status was determined from his or her medical records. The study statistician then randomly assigned the participants to the intervention or control study arm according to computer-generated random numbers. The research coordinator received the assignment codes in envelopes, which were concealed from all members of the research team and were not opened by the coordinator until the point of randomization. Participants who were smokers were stratified in the randomization process to equalize their distribution to the intervention and control groups; this stratification was performed by the statistician during the generation of random blocks. The outcome assessors were blinded to group allocation, and all data were collected without patients' knowledge of group allocation.

\section{Study intervention}

The intervention consisted of a report card (sent to the participant and his or her family doctor) showing the person's risk profile, coupled with a Telehealth-guided self-care management system. Framingham risk scoring methodology $^{13,14,16,17}$ was used to calculate a global risk score for cardiovascular disease. The Framingham risk factors were total and high-density lipoprotein cholesterol, systolic blood pressure, diabetes and smoking status. Physical activity, body mass index, waist circumference, nutrition status, stress level and health confidence were considered as key lifestyle factors.

A letter grading system (A, B, C, D, F) was developed for the risk scores, based on recommended risk guidelines for cardiovascular disease; ${ }^{16-19}$ staged target levels (i.e., the next grade level showing improvement) were developed for each patient, based on behavioural theories ${ }^{20,21}$ (Appendix I, available online at www.cmaj.ca/cgi/content/full/I77/8/859/DC2).

The Telehealth component of the intervention was conducted by 2 clinical lifestyle counsellors, both of whom were kinesiologists and had certification as clinical exercise specialists through the American College of Sports Medicine. The counsellors applied Canadian and US guidelines for cardiovascular disease prevention ${ }^{16-19}$ after receiving training in the use of motivational interviewing techniques for lifestyle counselling. Each counsellor examined half of the report cards of the participants in the intervention groups. On the basis of prior research, smoking was considered the top priority for lifestyle counselling, followed by physical activity, dietary habits, weight management and stress. If, for example, a subject received letter grades of A for smoking, D for exercise, D for nutrition, C for body mass index, and F for highdensity lipoprotein cholesterol, the counsellor would discuss physical activity and nutritional modifications with potential to affect high-density lipoprotein cholesterol, body mass index and other biomedical risk factors, in that order. Comparisons with previous report card grades were discussed with the participant to set new goals.

Telehealth counselling occurred within Io days of the patient receiving the annual report card and every 6 months thereafter for approximately 30 minutes per session, up to 60 minutes per year. Smokers prepared to quit received additional 20- to 30-minute sessions at 2, 4, 8 and I2 weeks according to $\mathrm{US}^{22}$ and Canadian ${ }^{23}$ guidelines. Summaries of each counselling session and supporting evidence-based educational materials were mailed to the participants. Control participants in the primary and secondary prevention groups received usual care from their physicians, based on their own determination of the need for visits. Typically, secondary prevention patients see their family doctors a minimum of twice per year to undergo blood pressure testing, to have their medications reviewed, and to have laboratory tests requested for liver enzymes and lipid levels. An annual graded exercise stress test is usually recommended.

\section{Data collection and measurement}

Clinical data were obtained annually for both intervention and control groups, as routinely collected and reported in health records, by biomedical laboratories and by family doctors' offices. Each participant and his or her family doctor received a reminder letter requesting the results of annual blood tests, and either the patient forwarded a copy of the test results to the research coordinator or the laboratory sent the results by fax. Other baseline and follow-up data were collected annually by means of telephone surveys administered by trained research assistants; these surveys typically took 45 minutes to complete. Survey questions pertained to the following self-reported secondary outcome variables: physical 
activity, body mass index, waist circumference, nutrition level, stress and health confidence. Physical activity data were collected according to a 5-point ordinal scale based on the American College of Sports Medicine's guidelines for physical activity in the prevention and rehabilitation of cardiovascular disease. ${ }^{19}$ Participants were asked to provide height and weight information to allow calculation of body mass index. They were also given instructions for measuring waist circumference at the level of the umbilicus; tape measures were mailed to participants who did not have one. ${ }^{24}$ Nutrition level was measured using a 5-point ordinal scale based on the number of recommended food groups met per day. ${ }^{25}$ Participants were asked to rate their level of stress (at the time of the telephone survey) on a Io-point scale, with Io being the highest level of stress that they had ever experienced and o being no stress at all. Health confidence was measured by the patient's response (on a Likert scale) to the question "How good of a job do you feel that you are doing in taking care of your general health? Would you say I (poor), 2 (fair), 3 (good) or 4 (excellent)?" As well, all participants were asked to provide sociodemographic information (age, sex, education and income), the names of their cardiovascular medications, and information to complete the 36 -item short-form healthsurvey. ${ }^{26}$ The same data were collected for all study participants regardless of group assignment.

\section{Primary outcome}

The primary outcome variable was the global cardiovascular risk score, according to the Framingham risk-scoring method, ${ }^{13,14,16,17}$ which combines smoking status (dichotomized into quit smoking for I year or not), ${ }^{14,22}$ total and high-density lipoprotein cholesterol, ${ }^{13,16,17}$ systolic blood pressure ${ }^{13}$ and fasting glucose level. ${ }^{13}$

It should be noted that changes in global risk scores do not necessarily translate into changes in outcomes. However, this approach has been applied to secondary prevention populations as a composite measure of change in risk factors, rather than as a predictor of risk..$^{10} \mathrm{~A}$ widely cited software tool developed in the United Kingdom has been used to evaluate response to treatment according to a similar measurement principle. ${ }^{27}$ The Framingham global risk score was used for the secondary prevention group as an indicator of cardiovascular risk, although this measure was not developed specifically for secondary prevention. ${ }^{13}$

\section{Statistical analysis}

The sample sizes used in this study generated statistical power of $80 \%$ at $\alpha=0.05$ (2-tailed) to detect intervention effect sizes of 0.35 or greater, based on similar interventions (specifically, the Stanford Coronary Risk Intervention Project). ${ }^{6,28}$ The clinical impact of this effect size for the primary outcome variables is difficult to determine, since the Framingham global risk score does not translate into change in cardiovascular disease.

An intention-to-treat approach was used for all participants in the primary and secondary prevention groups, and all missing data were imputed, as recommended for intention-to-treat analyses. ${ }^{29,30}$ Outcome data not collected at year I because of loss to follow-up were estimated by a multiple-imputation method based on valid responses to the 5 covariates. The covariates for statistical adjustment were selected because of their associations with the outcome variables, as reported in the literature. ${ }^{3,15,18}$ These covariates were age, sex, education level (5-category ordinal scale), income (7-category ordinal scale) and total score on the 36 -item short-form health survey. ${ }^{26}$ Missing data for the covariates were estimated as the mode for ordinal variables and the mean for interval variables.

Analyses of data for the 2 prevention groups were conducted separately. Group differences in I-year scores for all outcome variables were analyzed using the general linear model procedure to produce means, confidence intervals, analysis of variance $F$ scores and significance tests, except for change in smoking status. For change in smoking status, we used McNemar's test. The analyses of variance were repeated with adjustment for the covariates.

\section{Results}

We received a total of 2326 expressions of interest from potential participants, of whom 6II (26\%) met the 3 eligibility criteria (Figure I). A total of 1713 individuals did not meet all of the entry criteria, and 2 callers decided not to participate after the study was described.

The primary prevention group consisted of 315 participants who were randomly assigned to the intervention (157) and control (I58) groups. One-year outcome data were obtained for 278 participants. Data for a total of 37 participants (20 in the intervention group and 17 controls) were not available either through medical records or through contact with the patients because of no response, relocation, refusal or death. In the secondary prevention group, 296 participants were randomly assigned to the intervention (I53) and control (143) groups. One-year outcome data were obtained for 254 of these participants. Data for 42 patients (I5 in the intervention group and 27 controls) was not obtained for similar reasons as outlined for the primary prevention group.

For the primary prevention group, the baseline characteristics were similar between groups (Table I), except the global risk score was $\mathbf{1 2 . 5 5}$ for the intervention group and II.06 for the control group. The mean global risk score decreased between baseline and year I by 3.07 points for participants in the intervention group and by I.Io points for those in the control group $(F=9.84, p=0.002$ ) (Table 2).

For the secondary prevention group, the baseline characteristics were similar between the intervention and control groups. Between baseline and year I, the mean Framingham global risk score decreased by 0.42 points for participants in the intervention group and increased by 0.24 points for those in the control group $(F=0.13, p=0.7 \mathrm{I})$ (Table 2).

For the primary prevention group, with adjustment for covariates, significant group differences (in the expected direction) were found for the Framingham global risk score, total cholesterol, systolic blood pressure, nutrition level and health confidence (Table 3).

For the secondary prevention group, the changes in outcome measures for the intervention and control groups were 
not statistically significant either before or after adjustment for covariates (Table 3 ).

Many of the patients were followed in the same practice, so there was a potential for bias through contamination. The data were therefore checked for contamination by rerunning the analyses after removal of all participants (intervention or control) who shared a physician (5I in the primary prevention group and 48 in the secondary prevention group). The change in point estimates was less than $5 \%$, and all of the statistical associations remained unchanged. Because change in smoking status was measured in terms of whether the participant had quit at the start of the intervention and maintained nonsmoking status until the I-year follow-up, ${ }^{14,24}$ there were virtually no quitters (Table 3); therefore, the analyses for the primary and secondary prevention groups were repeated using the 6-month smoking cessation measurement; no statistically significant differences were found for any of the smoking analyses.

To examine potential mechanisms of outcome change, we analyzed differences between the intervention and control groups in terms of the self-reported number of medications prescribed for lipid control, hypertension, heart disease and diabetes between baseline and year $\mathrm{I}$. There were no statistically significant differences in the reported numbers (data not shown).

No differences in key outcomes were found between dropouts and nondropouts in the primary and secondary prevention groups. Furthermore, a sensitivity analysis in which the dropouts were ignored replicated the main results.

\section{Interpretation}

This study was an interdisciplinary collaborative research project involving a provincial health region and a university, in which a therapeutic lifestyle intervention, consisting of a report card combined with Telehealth counselling (averaging 30 minutes twice per year), was developed and tested. This frequency and intensity of counselling was lower than that of most cardiovascular disease prevention programs; for example, the Stanford Coronary Risk Intervention Project ${ }^{6}$ used a risk reduction intervention averaging 23.I visits during the 4 years of the trial. Analyses of baseline and I-year data showed a statistically significant reduction in global cardiovascular risk score for the intervention group, relative to the control group, within the primary prevention group. This association remained statistically significant after adjustment for age,

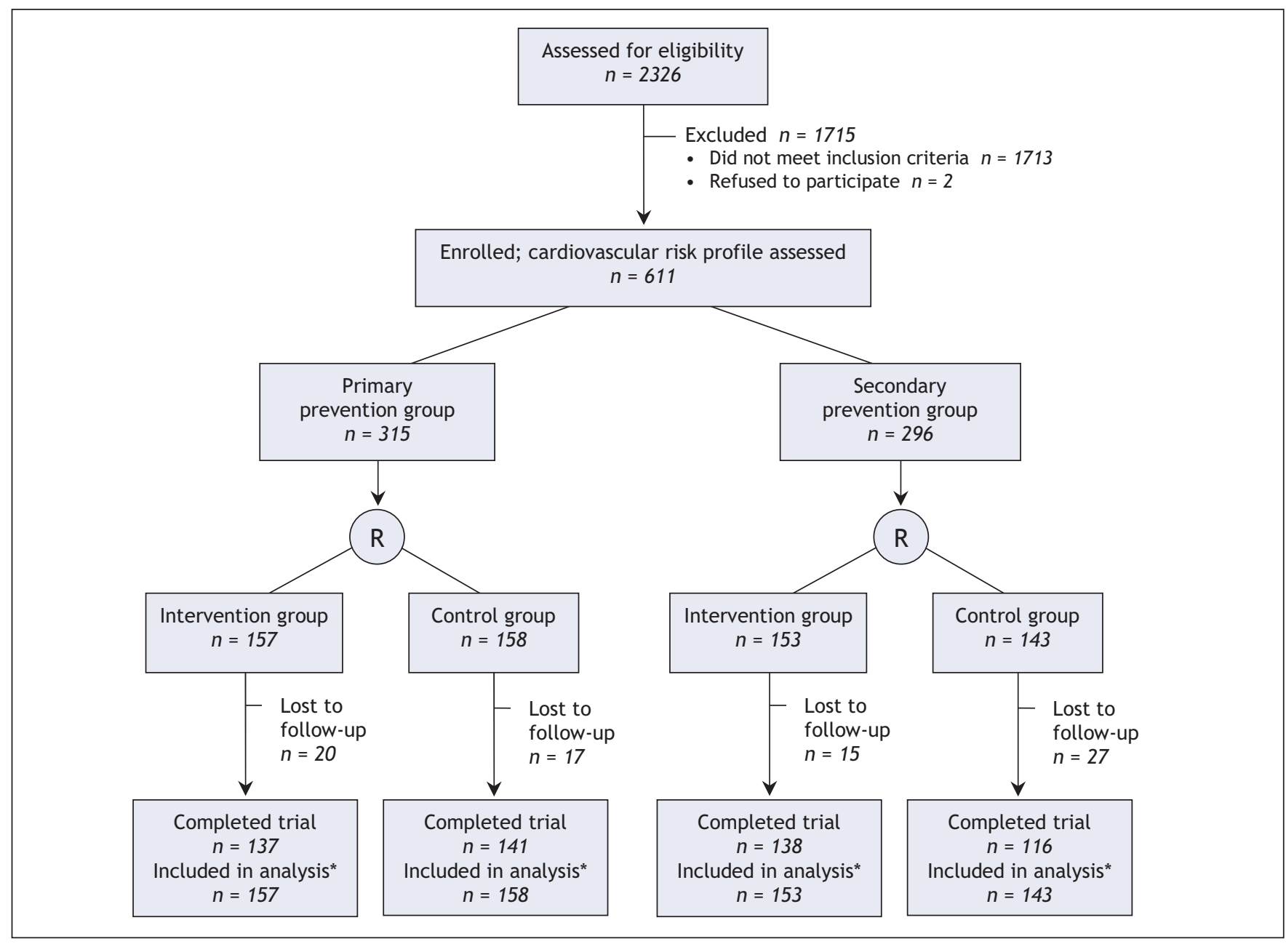

Figure 1: Flow of patients through the trial. $\mathrm{R}=$ randomization. ${ }^{\star}$ Data were imputed for the patients lost to follow-up. 
sex, education, income and total score on the 36 -item shortform health survey. Statistically significant improvements were also found for total cholesterol and systolic blood pressure, before and after adjustment for covariates. In addition, nutrition level and health confidence showed statistically significant increases. No support was found for the efficacy of the intervention for the secondary prevention group.

The findings of this study support previous research demonstrating the efficacy of interventions that have applied evidence-based recommendations for reduction of multiple cardiovascular risk factors, including smoking cessation, physical activity, weight management, nutrition and stress management in combination with monitoring of treatment programs ${ }^{4-8,10}$ Our study has shown that the intervention af- fected global risk of cardiovascular disease (lowering systolic blood pressure and total cholesterol) and lifestyle factors (improving nutrition level and lowering stress), but we were unable to examine coronary events over a longer period. The results support a positive effect only for primary prevention of cardiovascular disease and are consistent with very weak findings reported for a similar intervention and outcome measures in a study of secondary prevention of cardiovascular disease. ${ }^{10}$

One question that arises is whether the significant improvement in the Framingham global risk score was the result of better medical treatment or behavioural changes on the part of the individual through improvement in self-care practices. It might be speculated that both the individual and the physician play a role, as theorized in the expert patient model. ${ }^{9}$ Low-

Table 1: Descriptive statistics and baseline comparison of outcome variables and covariates

\begin{tabular}{|c|c|c|c|c|}
\hline \multirow{3}{*}{$\begin{array}{l}\text { Variable } \\
\text { Framingham global risk score, mean (SD) }\end{array}$} & \multicolumn{2}{|c|}{ Primary prevention group } & \multicolumn{2}{|c|}{ Secondary prevention group } \\
\hline & $\begin{array}{l}\text { Intervention } \\
\quad n=157\end{array}$ & $\begin{array}{l}\text { Control } \\
n=158\end{array}$ & $\begin{array}{l}\text { Intervention } \\
n=153\end{array}$ & $\begin{array}{l}\text { Control } \\
n=143\end{array}$ \\
\hline & $12.5 \quad(5.9)$ & $11.0 \quad(6.0)$ & $7.2(6.2)$ & $7.9 \quad(5.7)$ \\
\hline Total cholesterol, mmol/L, mean (SD) & $5.8 \quad(1.3)$ & $5.6 \quad(1.2)$ & $4.7 \quad(1.1)$ & $4.8 \quad(1.3)$ \\
\hline $\begin{array}{l}\text { High-density lipoprotein cholesterol, } \\
\mathrm{mmol} / \mathrm{L} \text {, mean (SD) }\end{array}$ & $1.3(0.3)$ & $1.3 \quad(0.3)$ & $1.3(0.4)$ & $1.2(0.3)$ \\
\hline Glucose, mmol/L, mean (SD) & $8.3 \quad(2.6)$ & $8.1 \quad(2.3)$ & $7.8 \quad(2.1)$ & $8.6 \quad(2.8)$ \\
\hline Systolic blood pressure, mm Hg, mean (SD) & $139.0(15.2)$ & $136.1(14.3)$ & $130.6(17.5)$ & $131.9(17.3)$ \\
\hline Smokers, no. (\%) & $22(14.0)$ & $20(15.6)$ & $17(11.1)$ & $17(11.9)$ \\
\hline \multicolumn{5}{|l|}{ Physical activity, no. (\%) } \\
\hline 4-6 times/wk (> $40 \mathrm{~min}$ ) & $37(23.6)$ & $39(24.7)$ & $54(35.3)$ & $55(38.5)$ \\
\hline 3-4 times/wk (21-40 min) & $50(31.8)$ & $32(20.3)$ & $45(29.4)$ & $38(26.6)$ \\
\hline 2-3 times/wk (11-20 min) & $25(15.9)$ & $32(20.3)$ & $23(15.0)$ & $10 \quad(7.0)$ \\
\hline$<2$ times $/$ wk $(<10 \mathrm{~min})$ & $45(28.7)$ & $55(34.8)$ & $31(20.3)$ & $40(28.0)$ \\
\hline Body mass index, $\mathrm{kg} / \mathrm{m}^{2}$, mean (SD) & $31.8 \quad(6.9)$ & $33.2 \quad(7.6)$ & $29.0 \quad(5.2)$ & $30.1 \quad(5.9)$ \\
\hline Waist circumference, $\mathrm{cm}$, mean (SD) & $105.7(17.2)$ & $108.1(17.7)$ & $99.3(14.6)$ & $102.4(15.5)$ \\
\hline \multicolumn{5}{|l|}{ Nutrition, ${ }^{*}$ no. $(\%)$} \\
\hline All 4 categories & $11 \quad(7.0)$ & $8 \quad(5.1)$ & $8 \quad(5.2)$ & $7 \quad(4.9)$ \\
\hline 3 categories & $35(22.3)$ & $49(31.0)$ & $42(27.5)$ & $35(24.5)$ \\
\hline 2 categories & $48(30.6)$ & $65(41.1)$ & $52(34.0)$ & $52(36.4)$ \\
\hline 0 or 1 category & $63(40.1)$ & $36(22.8)$ & $51(33.3)$ & $49(34.3)$ \\
\hline Perceived stress, $\uparrow$ mean (SD) & $5.2 \quad(2.6)$ & $5.1 \quad(2.6)$ & $5.1 \quad(2.3)$ & $4.3 \quad(2.5)$ \\
\hline \multicolumn{5}{|l|}{ Health confidence, no. (\%) } \\
\hline Poor & $16(10.2)$ & $11(7.0)$ & $6 \quad(3.9)$ & $10 \quad(7.0)$ \\
\hline Fair & $55(35.0)$ & $62(39.2)$ & $42(27.5)$ & $40(28.0)$ \\
\hline Good & $71(45.2)$ & $73(46.2)$ & $79(51.6)$ & $65(45.5)$ \\
\hline Excellent & $15 \quad(9.6)$ & $12(7.6)$ & $26(17.0)$ & $28(19.6)$ \\
\hline Age, yr, mean (SD) & $55.8 \quad(5.5)$ & $55.1 \quad(5.2)$ & $56.6 \quad(5.1)$ & $57.2 \quad(5.0)$ \\
\hline Sex, no. (\%) of men & $71(45.2)$ & $60(38.0)$ & $101(66.0)$ & $103(72.0)$ \\
\hline \multicolumn{5}{|l|}{ Marital status, no. (\%) } \\
\hline Married or common law & $103(65.6)$ & $108(68.4)$ & $122(79.7)$ & $107(74.8)$ \\
\hline Single, widowed, divorced or separated & $54(34.4)$ & 50 (31.6) & $31(20.3)$ & $36(25.2)$ \\
\hline
\end{tabular}

Note: $\mathrm{SD}=$ standard deviation

*With reference to categories specified in the Canada's Food Guide to Healthy Eating. ${ }^{25}$

†Stress was measured on a scale from 1 to 10, with higher scores indicating greater perceived stress. 
ering total cholesterol and systolic blood pressure in the intervention group may indicate closure of the care gap, since risk factors for cardiovascular disease tend to be more effectively controlled by means of prescription therapy than by changes in lifestyle. ${ }^{16-18}$ Significant improvement in nutrition level and health confidence in the intervention group suggests that some individual behavioural and/or psychosocial change took place, which is consistent with studies that aimed for reduction in multiple risk factors. ${ }^{4-8}$ Finally, it is possible that the lack of change for the secondary prevention group related to a floor effect, as indicated by the low baseline global risk scores. This may be indicative of a smaller treatment gap for these participants, many of whom were receiving concurrent cardio- vascular disease assessment and therapy and/or cardiac rehabilitation based on clinical guidelines.

There were limitations to this research. First, the sample sizes were only large enough to detect effect sizes of approximately 0.35 . For the secondary prevention group, the bounds of the $95 \%$ confidence intervals on the difference between groups excluded values that might be considered clinically important. Second, participants in the control (and intervention) groups and their doctors received reminders to provide annual results of blood work, which might have affected their outcomes through increased monitoring of their risk factors. Third, some of the lifestyle measures we used are crude, and we may not have captured all lifestyle changes. Fourth, use of

Table 2: Changes in Framingham risk score between baseline and year 1

\begin{tabular}{|c|c|c|c|c|c|c|}
\hline \multirow[b]{2}{*}{ Group } & \multicolumn{5}{|c|}{ Framingham risk score $(95 \% \mathrm{Cl})$} & \multirow[b]{2}{*}{$F$ value, $p$ value } \\
\hline & & Baseline & Year 1 & Absolute difference & $\%$ change & \\
\hline Primary prevention & & & & & & $F=9.84, p=0.002$ \\
\hline Intervention & 12.55 & (11.56 to 13.54$)$ & 9.48 (8.64 to 10.32 ) & $-3.07(-3.94$ to -2.20$)$ & 24.5 & \\
\hline Control & 11.06 & (10.11 to 12.01$)$ & 9.96 (9.10 to 10.82$)$ & $-1.10(-1.97$ to -0.23$)$ & 9.9 & \\
\hline Secondary prevention & & & & & & $F=0.13, p=0.71$ \\
\hline Intervention & 7.17 & (6.18 to 8.16$)$ & 6.75 (5.88 to 7.62$)$ & $-0.42(-1.12$ to 0.28$)$ & 5.9 & \\
\hline Control & 7.87 & (6.92 to 8.82$)$ & 8.11 (7.25 to 8.97$)$ & $0.24(-0.48$ to 0.96$)$ & 3.0 & \\
\hline
\end{tabular}

Note: $\mathrm{Cl}=$ confidence interval.

Table 3: Change in outcome variables between baseline and year 1, with adjustment for age, sex, education, income and 36-item short form health survey ${ }^{26}$

Absolute difference $(95 \% \mathrm{Cl})$

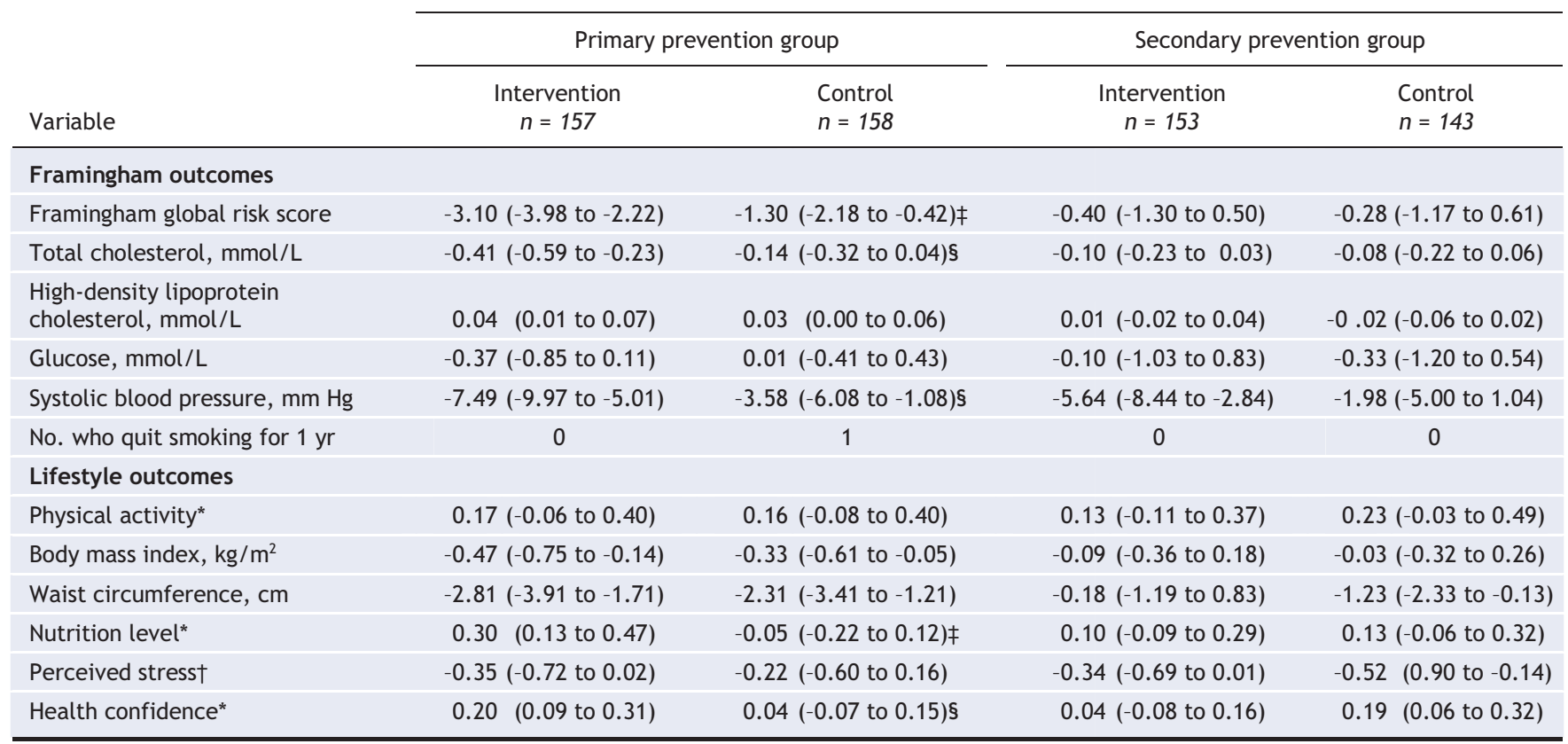

Note: $\mathrm{Cl}=$ confidence interval.

*The ordinal measures physical activity, nutrition level and health confidence were treated as continuous variables.

†Stress was measured on a scale from 1 to 10 , with higher scores indicating greater perceived stress.

$\neq p<0.01$.

sp $<0.05$ 
the Framingham score for the secondary prevention group is controversial, since it was originally developed for primary prevention. Fifth, it is possible that the 2 lifestyle counsellors used in this study are not representative of all professionals certified by the American College of Sports Medicine. Sixth some measures were self-reported or involved measurement by the participant (e.g., body mass index and waist circumference), which may have resulted in some degree of measurement error. Finally, we were unable to examine whether the intervention was efficacious for different ethnic groups because of the cost of translation, and our sample may therefore not be fully representative.

The findings of this study suggest that self-care approaches to reduction of cardiovascular disease risk can work when integrated with the primary health care system. There may also be potential for innovative health promotion strategies that use methods for self-monitoring of risk levels and guidelines for reaching individualized targets. Furthermore, expansion of health policies and programs that encourage individuals to prevent cardiovascular disease by changing and sustaining more healthy lifestyles is recommended.

In conclusion, this study provides evidence for the efficacy of an easily administered health report card and Telehealth counselling intervention for primary prevention of cardiovascular disease. Future research is needed to elucidate the mechanisms of reducing risk and to develop and test the efficacy and effectiveness of similar interventions.

This article has been peer reviewed.

Competing interests: None delcared.

Contributors: All of the authors contributed substantially to the conception and design of the study, acquisition of data, and analysis and interpretation of the data; drafted the article and revised it critically for important intellectual content; and gave final approval of the version to be published.

Acknowledgements: We thank Dr. Mark Speechley, Associate Professor, Department of Epidemiology, University of Western Ontario, and Dr. Scott Lear, Assistant Professor, Department of Kinesiology, Simon Fraser University, for their helpful comments, and Doug Talling, Consultant, BC Centre for Disease Control, for his statistical support.

This study was funded by the Canadian Institutes of Health Research, Community Alliance for Health Research Program, project 43267.

\section{REFERENCES}

I. Heart and Stroke Foundation of Canada. The growing burden of heart disease and stroke in Canada. Ottawa: The Foundation; 2003.

2. Chen J, Millar WJ. Are recent cohorts healthier than their predecessors? Health Rep 2000; II(4):9-23

3. Wister AV. Baby boomer health dynamics: How are we aging? Toronto: University of Toronto Press; 2005.

4. DeBusk RF, Miller NH, Superko R, et al. A case-management system for coronary risk factor modification after acute myocardial infarction. Ann Intern Med 1994;I20:72I-9.

5. Gordon NF, Salmon RD, Franklin BA, et al. Effectiveness of therapeutic lifestyle changes in patients with hypertension, hyperlipidemia, and/or hyperglycemia. Am JCardiol 2004;94:1558-6r.
6. Haskell WL, Alderman EL, Fair JM, et al. Effects of multiple risk factor reduction on coronary atherosclerosis and clinical cardiac events in men and women with coronary artery disease. The Stanford Coronary Risk Intervention Project (SCRIP). Circulation I994;89:975-90.

7. Knoops KT, de Groot LC, Kromhout D, et al. Mediterranean diet, lifestyle factors, and Io-year mortality in elderly European men and women: the HALE Project. JAMA 2004;292:1433-9.

8. Stampfer MJ, Hu FB, Manson JE, et al. Primary prevention of coronary heart disease in women through diet and lifestyle. N Engl J Med 2000;343:16-22.

9. Expert Patients Task Force. The expert patient: a new approach to chronic disease management for the 2Ist century. London (UK): Department of Health; 2000.

Io. Lear SA, Ignaszewski A, Linden W, et al. The Extensive Lifestyle Management Intervention (ELMI) following cardiac rehabilitation trial. Eur Heart J 2003;24:I920-7.

II. Wing RR, Goldstein M, Acton K, et al. Behavioral science research in diabetes: lifestyle changes related to obesity, eating behavior, and physical activity. Diabetes Care 200I;24:117-23.

I2. O'Connor B, Cameron R, Farquharson J, et al. Marketing the heart health vision delivering the "preventive dose." Ottawa: WHO Collaborating Centre for Policy Development in the Prevention of Noncommunicable Disease; 2000.

I3. Grundy SM, Pasternak R, Greenland P, et al. Assessment of cardiovascular risk by use of multiple-risk-factor assessment equations. A statement for healthcare professionals from the American Heart Association and the American College of Cardiology. Circulation I999;100:I48I-92.

I4. Wilson PW, D'Agostino RB, Levy D, et al. Prediction of coronary heart disease using risk factor categories. Circulation I998;97:1837-47.

15. Canadian Community Health Survey (CCHS 3.I). Risk factors for heart disease in midlife (45-64 years). Fraser Health. Ottawa: Statistics Canada. 2005

I6. Grundy SM, Becker D, Clark LT. Third report of the National Cholesterol Education Program (NCEP) Expert Panel on Detection, Evaluation, and Treatment of High Blood Cholesterol in Adults (Adult Treatment Panel III): executive summary. NIH Publ. no. oI-3670. Washington (DC): National Institutes of Health, National Heart, Lung, and Blood Institute; 200r. Available: www.nhlbi.nih.gov/guidelines /cholesterol/atp_iii.htm (accessed 200I Sep ro).

I7. Genest J Jr, Frohlich J, Fodor G, et al. Guidelines for the management and treatment of dyslipidemia and prevention of cardiovascular disease: summary of the 2003 update. $C M A J$ 2003;I69:92I-4.

I8. Canadian Association of Cardiac Rehabilitation. Canadian guidelines for cardiac rehabilitation and cardiovascular disease prevention. Enhancing the science, refining the art. 2nd ed. Winnipeg: The Association; 2004.

I9. American College of Sports Medicine. ACSM's guidelines for exercise testing and prescription. 6th ed. Philadelphia: Lippincott Williams \& Wilkins; 2000.

20. Marcus BH, Bock BC, Pinto BM. Initiation and maintenance of exercise behavior. In: Gochman DS, editor. Handbook of health behavior research II: Provider determinants. New York: Plenum Press; 1997. p. 336-9.

2I. Marcus BH, Selby VC, Niaura RS, et al. Self-efficacy and the stages of exercise behavior change. Res Q Exerc Sport I992;63:60-6.

22. Clinical practice guideline. Treating tobacco use and dependence. Washington: US Department of Health and Human Services, Public Health Service; 2000.

23. BC Doctors Stop Smoking Program. A program of the Society for Clinical Preventive Health Care. Vancouver: Society for Clinical Preventive Health Care; 200I. Available: www.bcdssp.com (accessed 200I Nov 15).

24. Clark A, Berra K. Stanford Hear ${ }^{2}$ t Program (Health Education and Risk Reduction Training Program). Stanford (CA): Stanford University, Stanford Center for Research in Disease Prevention; 200I.

25. Canada's food guide to healthy eating for people four years and over. Ottawa: Health Canada; 1997

26. Ware JE Jr, Sherbourne CD. The MOS 36 -item short-form health survey (SF-36). I Conceptual framework and item selection. Med Care 1992;30:473-83.

27. Hingorani AD, Vallance P. A simple computer program for guiding management of cardiovascular risk factors and prescribing. BMJ I999;318:I0I-5.

28. Lipsey M. Design sensitivity: statistical power for experimental research. New York: Sage; 1990.

29. Hollis S, Campbell F. What is meant by intention to treat analysis? Survey of published randomized controlled trials. BMJ I999;319:670-4

30. Fergusson D, Aaron SD, Guyatt G, et al. Post-randomization exclusions: the intention to treat principle and excluding patients from analysis. BMJ 2002;325:652-4.

Correspondence to: Dr. Andrew V. Wister, Professor and Chair, Department of Gerontology, Simon Fraser University, Vancouver Campus, 2800-515 W Hastings St., Vancouver BC V6B 5K3; fax 604 29I-5066; wister@sfu.ca 